\title{
Finding the Finals Fairy
}

\section{Outreach and stress release during finals}

$\mathbf{S}$ alisbury University (SU) Libraries has a visitor who comes at the end of every semester, staying for approximately one week. Her name is familiar to the students, and her arrival is heralded on social media and via posters around campus. She is the Finals Fairy. She serves many purposes, but her primary function is to provide stress relief to students in the midst of their finals. Susan Brazer first came up with the idea in the fall 2011, and SU Libraries has continued with her every fall and spring semester since.

In 2011 National Public Radio (NPR) ran a news story about an artist in Scotland who had started a massive "hide-and-seek" game, using her book-themed art left at various places around Edinburgh along with a clue giving seekers an idea of where the next prize would be found. ${ }^{1}$ That news story sparked the idea of SU Libraries trying something similar, albeit significantly smaller in scale. With a budget well under $\$ 100$, it was organized and implemented less than 24 hours later. Due to the short turn-around time and small budget, dollar store prizes, including plastic toys and candy, made up the bulk of the prizes, and the grand prize was a $\$ 15$ Chipotle gift card. The first prizes were hidden in the library building, and clues were sent out via social media.

However despite all hopes, students either weren't interested or didn't understand how Finals Fairy, named purely for whimsical alliterative reasons, worked.
The first few prizes were left on the shelf, unclaimed and unwanted. Library colleagues took it on themselves to send out a few faux-tweets on their personal Twitter accounts claiming to have found prizes, and expressing their excitement that the library was hiding free and fun prizes for anyone who was studying in the library. Those few encouraging tweets were all it took, and less than 12 hours later, the students had fully grasped the concept of the Finals Fairy, and the race was off to see which studying undergraduate could find the prizes first. It is a program that continues eight years later.

Currently, volunteers are requested and sourced from the entire library staff via an email call for participation. Research and instructional librarians participate most regularly, but volunteers range from the technology librarian, to the local history archivist, to the libraries' executive administrative assistant. Student workers are drafted from the circulation desk to help with hiding prizes on the weekends, when no librarians are present. The committee is formed newly each semester to design and approve posters with the University

\footnotetext{
Angeline Prichard is a research and instructional librarian and RIS department chair, email: arprichard@ salisbury.edu, and Susan Brazer is science research and instruction librarian, as well as the open resources and data management coordinator, email: sebrazer@ salisbury.edu, at Salisbury University Libraries
}

(C) 2020 Angeline Prichard and Susan Brazer 
Publications office, review the prizehiding schedule, and purchase prizes themselves.

Over the history of SU's Finals Fairy, the budget has varied widely, and the committee has found that it is an easily scalable process in either direction. Prizes can be free library merchandise or donated materials from local businesses if the budget demands or can also extend to larger grand prizes. In a recent budget cycle, the dean provided $\$ 300$ per semester for the initiative, paying for both advertising and prizes. More specifically, that breakdown was as follows:

\begin{tabular}{|l|l|}
\hline Advertising posters & $\$ 60$ \\
\hline Grand prize | Kindle paper white & $\$ 80$ \\
\hline Dollar Store prizes & $\$ 50$ \\
\hline Starbucks gift cards | $13 @ \$ 5$ & $\$ 65$ \\
\hline Chipotle gift cards | 4 at \$10 & $\$ 40$ \\
\hline Weekend candy | 4 bars & $\$ 5$ \\
\hline Total & $\mathbf{\$ 3 0 0}$ \\
\hline
\end{tabular}

In the early Finals Fairy days, the committee did not have any formal means of promoting the event, nor was there a budget that truly allowed for slick promotional items. The committee began simply, with basic social media posts announcing the Finals Fairy's arrival, and used hand-drawn representations of the Finals Fairy all around campus-including chalk drawings on campus side-

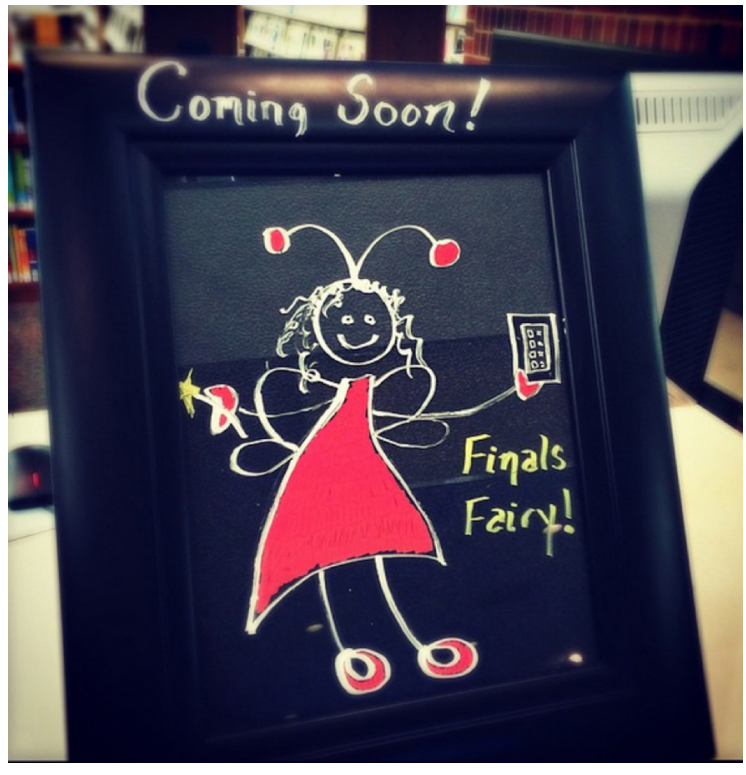

the three time slots for each day of finals, in which volunteers sign up for the prizes they will be responsible for hiding. The prizes themselves are laid out on a table by time slot. Committee members collect the prizes they will be hiding to bring back to their own workspaces, thus diversifyWhen the Finals Fairy initiative first started, simple chalk- ing where the paint drawings such as this one served as the main form prizes come of advertisement.

from and re- 
ducing notice from students. Over the weekends, a variety of themed prizes have been explored, including caffeinated drinks, vitamin-boosted water, and candy.

When hiding the prizes, volunteers must take a picture of the item in situ with a clue, as stealthily as possible. This is then cross posted to the library's Instagram, Twitter, and Facebook accounts. Ultimately, the hope is that while the primary purpose is to help students destress during the most stressful time of their semester, searching for clues will also help familiarize them with areas of the building with which they are less accustomed. Along with each prize, two small sheets of paper are hidden. One says "You Found Me" with information

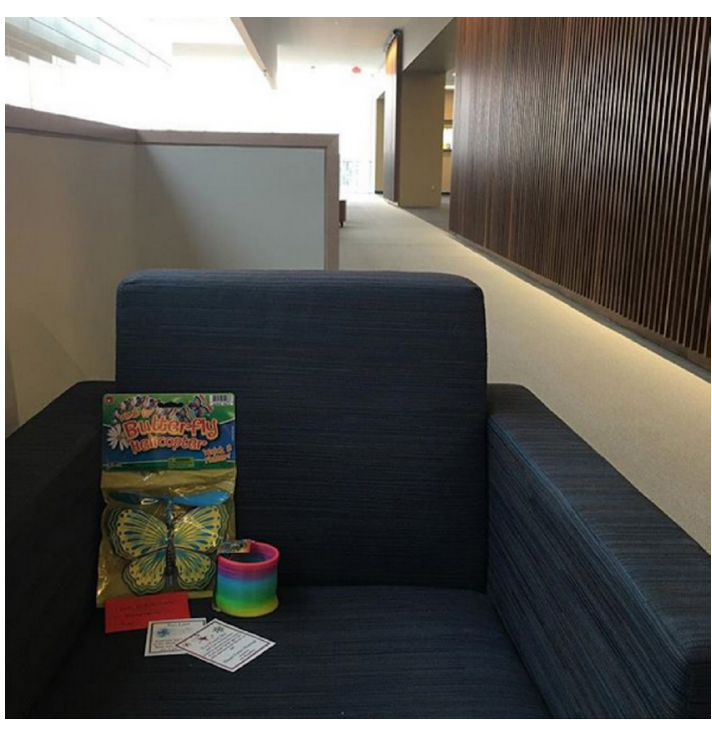

Finals Fairy gifts, such as this "Butterfly Helicopter" and Slinky, are tucked away in various places of the Guerrieri Academic Commons for students to hunt for during their final exam studies. about the \#finals-

fairy hashtag and SU Libraries' social media accounts. This encourages students to reply to the library via social media that they have found the prize. Not only does that indicate to any students who stumble onto the post later to see that a prize has been found, but it also encourages friendly interactions between the library and the students on social media. The second paper left with the prize signals to anyone who is searching that the prize has already been found but more are on the way.

Organizers wanted a little more control over the grand prize due to its monetary value. As such, each year a winning ticket is hidden in place of the prize itself. This ticket must be brought to the library service desk, where a committee member is waiting, to be exchanged for the prize. To create a little continuity between semesters, this ticket is always hidden in the same way. The winning ticket is hidden inside of one book. This book is placed in a stack of several other books, and a photo is taken showing all of the spines. The caption used in the final prize social media posting is a clue referencing which book in the stack has the slip in it- "Can you dig up the right book?"-in reference to an archaeology text, for instance.

Each year, once the social media post goes live, multiple students can be seen running about the building, trying to figure out how to track down the correct call number and be the first to discover the winning ticket.

Even with the excitement of the grand prize search, students have remained respectful of their fellow students who are studying. The libraries have received no complaints about noise or disruption for any Finals Fairy-related searching.

Overall, things have run relatively smoothly with implementing the Finals Fairy, but there have been obstacles along the way. Each semester there are always a few students who are repeat finders. While this did not present a problem for the smaller prizes, the com- 
mittee was dismayed to discover that twice the same student found the grand prize in back-to-back semesters.

To limit this, advertisements and the social media post announcing the grand prize now include a note that previous grand prize winners are not eligible for subsequent grand prizes. Organizers also keep a running list of grand prize winners to reference when a grand prize winner presents

the winning ticket.

Additionally, there have been times when students have followed a staff member while a prize is being hidden. This has resulted in a prize, particularly a grand prize, which has needed to be re-hidden. If the committee

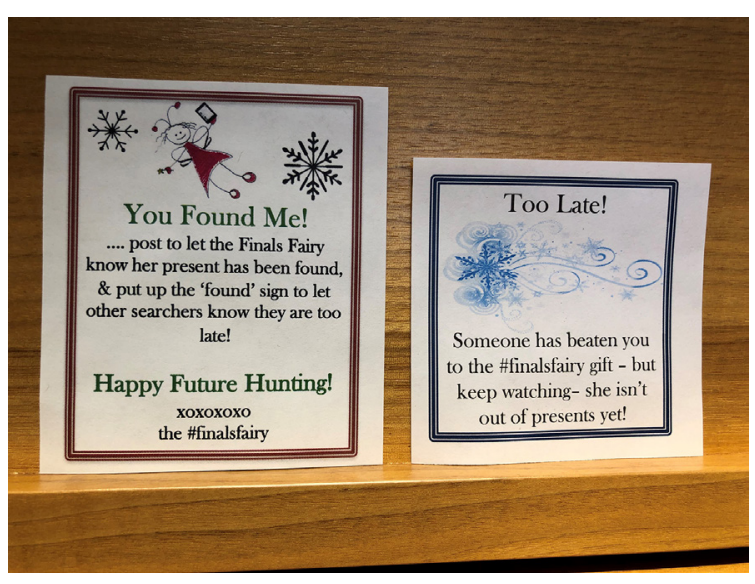

"You Found Me!" slips are included with each prize. Matching "Too Late!" slips are positioned underneath each gift to be left behind. scaled up as budget or institution permits. SU Libraries' program started with donations from local businesses and a \$15 grand prize, but has been scaled up to include prizes hidden three times a day, gift cards, and a grand prize that hovers just under the $\$ 100$ mark.

In the event of a budget increase, organizers have discussed designing and ordering customized Finals Fairy swag, like branded pens, mugs, t-shirts, and drawstring b a c k p a cks. Even with only a few items to hide, students were excited by the libraries' efforts to reach out and support them in a stressful time.

The prizes themselves didn't seem to actually matter in the long run, but were a wonmakeup can be varied from semester to semester, this would help eliminate much of that problem. If not, removing the prizes from being stored in a central public location has certainly decreased the students' ability to track staff members hiding habits.

Library student employees might also be used in hiding prizes to reduce students' abilities to track those hiding. Likewise, willing student employees might be used in the initial launch of a Finals Fairy program to get it off the ground by "finding" the first prize(s) and announcing it via their own social media accounts.

Overall, the Finals Fairy program has been an extremely rewarding outreach endeavor. Undertaken with a small amount of funding and staff, this is a program that can be easily started, easily funded, and derful avenue with which to reach out to and support hard-working students as they spent their long hours in the library studying for final exams.

While it does not need to be a fairy that visits your campus, does not require a grand prize, and can contain as many or as few cheap prizes as are deemed suitable, a similar outreach and support mission targeted towards students during their high-stress times would surely be as rewarding as the Finals Fairy is at Salisbury University.

\section{Note}

1. Robert Krulwich, "Who Left a Tree, Then a Coffin in the Library?" NPR, October 31, 2011, https://www.npr.org/sections /krulwich/2011/10/28/141795907/wholeft-a-tree-then-a-coffin-in-the-library. $z$ 